\title{
Do steroid hormones have an important role on cutaneous lupus physiopathology?*
}

\author{
Ana Brasileiro ${ }^{1}$
}

Sara Campos ${ }^{1}$

Ana Fidalgo $^{1}$

DOI: http://dx.doi.org/10.1590/abd1806-4841.20154387

Sir,

An 80-year-old-Caucasian-woman has been followed during the last 25 years for cutaneous discoid lupus erythematosus (CDLE) without systemic involvement. The lesions, limited to the face, ears and scalp, had been controlled with photoprotection, topical corticosteroids, topical calcineurin inhibitors and hydroxychloroquine, combined intermittently with intralesional and systemic steroids. Her medical history was otherwise not relevant and she had never been a smoker.
Four years ago she underwent radical left mastectomy for carcinoma ductal in situ with positive oestrogen receptors, followed by hormonotherapy with letrozole $2,5 \mathrm{mg} /$ day. A month later there was pronounced cutaneous worsening and the lesions became refractory to previously effective therapies (Figure 1). There were no other recently started medications or systemic complaints; routine blood laboratory tests and autoimmunity antibodies were within normal range. Acitretin $25 \mathrm{mg}$ / day was attempted but
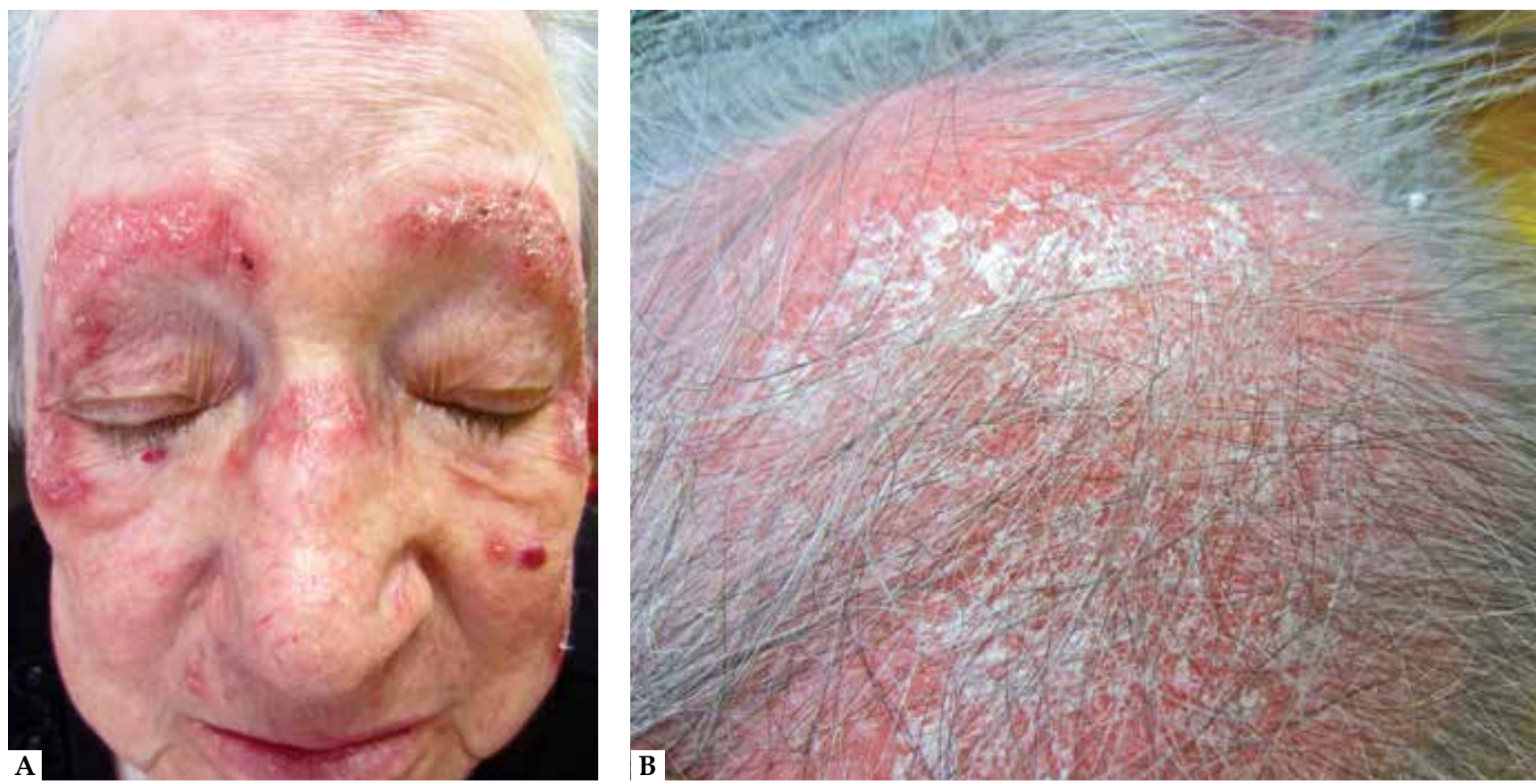

FIGURE 1: A: Multiple well-defined erythematous plaques distributed over convex areas of the face; B: Marked inflammatory infiltration of the scalp with follicular plugging, adherent scale and alopecia

Received on 10.01.2015

Approved by the Advisory Board and accepted for publication on 19.02.2015

Work carried out at the Hospital S. António dos Capuchos - Centro Hospitalar Lisboa Central - Lisbon, Portugal. Financial Support: None.

Conflict of Interest: None.

1 Hospital S. António dos Capuchos - Centro Hospitalar Lisboa Central - Lisbon, Portugal.

(C2015 by Anais Brasileiros de Dermatologia 


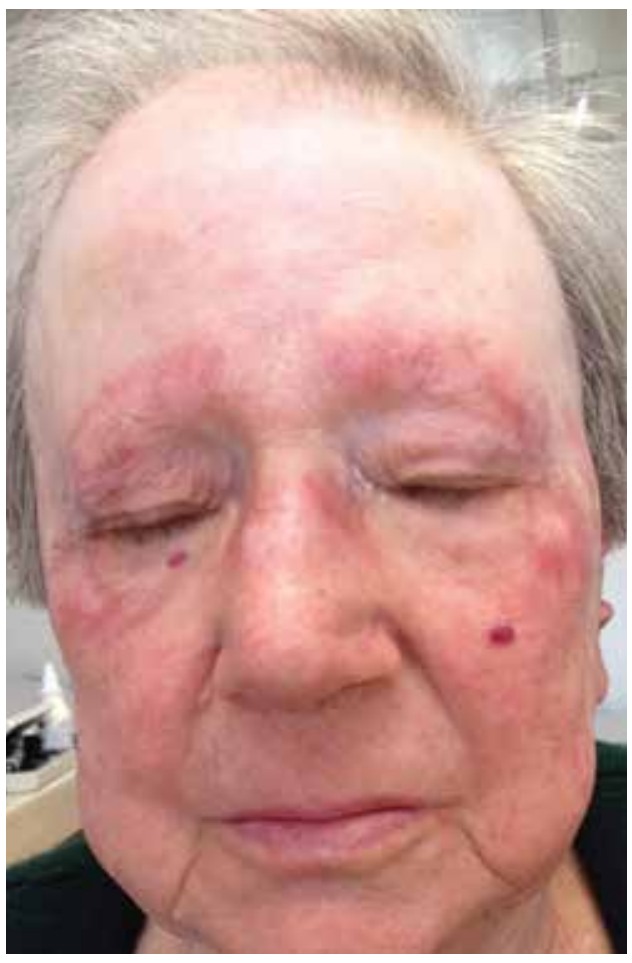

Figure 2: Improvement of facial lesions with residual plaques there was further clinical worsening and immunosuppressive therapies were contraindicated by the recent malignant neoplasia. Thalidomide $50 \mathrm{mg} /$ day was then combined with previous therapies, with marked clinical improvement within two weeks, allowing the discontinuation of systemic steroids and hydroxychloroquine (Figure 2). Sustained therapeutic efficacy was observed over one-year follow-up despite maintenance of letrozole therapy. No significant side effects have occurred.

Lupus erythematosus (LE) has three major subtypes: systemic lupus erythematosus (SLE), subacute lupus erythematosus (SCLE) and cutaneous discoid lupus erythematosus (CDLE). The pathogenesis is not well known - it is believed to stem from interplay between genetic and environmental factors. Ultraviolet radiation and immune dysregulation of innate and acquired immune responses have been implicated. ${ }^{1}$ Hormonal-influenced mechanisms might also play a role in LE. The skin is an independent steroidogenic organ, and cutaneous steroidogenesis has effects on local immunologic activity. Oestrogen stimulates the production of interferon-y, interleukin 1, 5, 6 and 10, increases B-cell survival, enhances antibody production and contributes to the persistence of autoreactive T-cells in SLE patients. ${ }^{2}$

Additionally, epidemiological data supports a role for sexual hormones in lupus susceptibility. ${ }^{1}$ An estimated three-fold female predominance among patients with cutaneous lesions only has been observed. ${ }^{1}$ The female preponderance is even higher in SLE patients, occurring most commonly in reproductive-age women and being rare in prepubertal age. ${ }^{1}$ Furthermore, reported cases of hormonal-induced SLE and anti-oestrogen drug-induced SCLE, namely anastrozole and tamoxifen, also suggest a role for hormonal imbalance in LE pathogenesis. ${ }^{3-5}$ However, no case of CDLE induced or aggravated by such therapies has been reported to date.

Letrozole is a third-generation aromatase inhibitor indicated for hormone-sensitive breast cancer in postmenopausal women. Its anti-oestrogenic effects induce nearly complete suppression of aromatization in all tissues. Theoretically, aromatase inhibitors should be beneficial in lupus patients, once they reduce cutaneous estradiol production which stimulates inflammatory pathways. Conversely, in our patient, letrozole paradoxically aggravated the disease, perhaps due to iatrogenic hormonal imbalance, which points towards a pathogenic role for cutaneous hormonal dysregulation in CLE.

Considering that both pathologies are not rare, probably more CLE women will undergo anti-oestrogen therapy for breast cancer. Whether the cutaneous disease will have the same behaviour as in our patient remains unknown. Further studies are warranted to access the effect of aromatase inhibitors in CLE patients. $\square$ 


\section{REFERENCES}

1. Bolognia JL, Jorizzo JL, Rapini RP. Dermatology. 3rd ed. Mosby: Elsevier; 2012. p. 615-629.

2. Kim WU, Min SY, Hwang SH, Yoo SA, Kim KJ, Cho CS. Effect of oestrogen on T cell apoptosis in patients with systemic lupus erythematosus. Clin Exp Immunol. 2010;161:453-8

3. Chan KL, Mok CC. Development of systemic lupus erythematosus in a male-tofemale transsexual: the role of sex hormones revisited. Lupus. 2013;22:1399-402.

4. Trancart M, Cavailhes A, Balme B, Skowron F. Anastrozole-induced subacute cutaneous lupus erythematosus. Br J Dermatol. 2008;158:628-9.

5. Fumal I, Danchin A, Cosserat F, Barbaud A, Schmutz JL. Subacute cutaneous lupus erythematosus associated with tamoxifen therapy: two cases. Dermatology. $2005 ; 210: 251-2$.
MAILING ADDRESS:

Ana Brasileiro

Alameda Santo António dos Capuchos 1169-050

Lisbon, Portugal.

E-mail:afmbrasileiro@gmail.com

How to cite this article: Brasileiro A, Campos S, Fidalgo A. Do steroid hormones have an important role on cutaneous lupus physiopathology? An Bras Dermatol. 2015; 90(5):766-8. 